\title{
As representações sociais de adolescentes do Ensino Médio sobre as redes sociais
}

\section{Social representations of high school teenagers on social networks}

\author{
Débora Magna de Almeida Duarte ${ }^{1 *}$, Luana Michele da Silva Vilas Bôas ${ }^{2}$
}

\begin{abstract}
RESUMO
Este trabalho consiste em uma pesquisa de abordagem quantitativa, de natureza descritiva e do tipo transversal e tem como objetivo descrever e analisar as representações sociais dos estudantes do ensino médio, acerca das redes sociais e as possíveis implicações na autoimagem desses jovens. Foi aplicado um questionário com questões fechadas, por meio do Google Forms onde 32 adolescentes responderam um questionário que continha 7 questões de identificação do participante e 11 questões específicas sobre o tema. Conclui-se que as redes sociais interferem na autoimagem que o adolescente constrói de si, com mais frequência no sexo feminino.
\end{abstract}

Palavras-chave: Adolescentes; Autoimagem; Redes Sociais

\section{ABSTRACT}

This work consists of a research with a quantitative approach, descriptive and cross-sectional and aims to describe and analyze the social representations of high school students about social networks and the possible implications for the self-image of these young people. A questionnaire with closed questions was applied, through Google Forms, where 32 adolescents answered a questionnaire that contained 7 participant identification questions and 11 specific questions on the topic. It is concluded that social networks interfere with the self-image that adolescents build of themselves, more often in females.

Keywords: Teenagers; Self-image; Social networks

\footnotetext{
${ }^{1}$ Faculdade Católica Salesiana.

*Email: deboramaduarte@gmail.com
} 


\section{INTRODUÇÃO}

Este trabalho visa estabelecer qual é a representação social dos adolescentes do ensino médio, e a relação dessas representações sociais com as redes sociais e suas implicações na autoimagem dos mesmos. O veículo dessa representação são alunos ingressantes do ensino médio e do último ano do ensino médio.

As representações sociais podem ser definidas como "imagens construídas sobre o real" (MYNAIO, 1994 apud ARAÚJO, 2008, p.100). Essas são elaboradas a partir da relação que o indivíduo possui com o grupo social em que está inserido. Este desenvolvido pelo espaço público, que é onde esse grupo debate e cristaliza saberes sobre si próprio, o que então é chamado de representação social. Essas são marcadas por um dinamismo e relacionadas à trajetória do grupo que a elaborou. São destacadas pelas ações coletivas dos indivíduos, porém, implicando em um reflexo das relações estabelecidas dentro e fora do grupo, isso a partir das referências do contato com outro indivíduo ou outros grupos sociais.

Segundo Moscovici (1978) apud Araújo (2008), determinados conceitos da psicanálise eram manejados no cotidiano de uma parcela da sociedade, levando em consideração que o conhecimento científicoestá para além de suas demarcações. Sendo assim, pôs-se em vigor que o conhecimento se constitui por intermédio de dois viés, o institucional e o do senso comum. Seguindo pelo ramo institucional, melhor compreendido pelo meio acadêmico, o mesmo retém uma pequena parcela de $2 \%$ a $3 \%$ do conhecimento. Outrossim, o senso comum coordena o senso prático. Nota-se que o que orienta um indivíduo a agir de determinado modo na sociedade, é o conhecimento prático, derivado do senso comum. Esse por sua natureza, é adquirido a partir de vivências que permeiam o grupo social em que esse indivíduo está inserido. A partir dos conceitos esclarecidos, observa-se que as representações sociais são o conjunto de ideias, explicações e coerências que são resultados da interação social de cada homem.

Moscovici (1978) apud Araújo (2008) destacou uma perspectiva coletiva sem preterir o indivíduo, pois esse possui características próprias. Diante do proposto, vê-se que as representações sociais são geradas através da informação, campo cognitivo e atitude. Mediante a informação oferecida, o indivíduo organiza o conhecimento, o campo cognitivo oportuniza a formulação de uma imagem com base no armazenamento de conhecimento a respeito de algo que está sendo informado e a atitude diz respeito ao posicionamento perante ao que está sendo exposto. A partir deste, inicia-se o processo da produção da representação social que o indivíduo irá gerar acerca de algo.

Enfatizando a mídia, como exemplo, ela usufrui de um monopólio de informações, ou seja, organiza o conhecimento e expõe as informações de modo arbitrário, tendenciosamente, 
para benefício próprio. Perante o que é exposto pelas redes, o ser internaliza a informação e produz o seu próprio ponto de vista. Entretanto, a maneira em que a informação é transferida para o sujeito, possui uma grande influência na forma de como será criada essa representação social que o mesmo terá acerca do objeto que está sendo informado. A teoria das representações sociais está interligada com a teoria do pensamento social, cujo é compartilhado entre o grupo.

Partiu-se do pressuposto que o levantamento das representações sociais é uma teoria facilitadora para ainvestigação do tema proposto, na medida em que, a adolescência é marcada pelo desenvolvimento de valores que estará presente no comportamento dos jovens ao decorrer de sua vida, além de interferir na sua identidadepessoal e sua relação com os outros. (LOPES, 2017 apud COPETTI; QUIROGA) Passos et al. (2013) afirma que com as mudanças, principalmente físicas, do jovem no período da puberdade, surge também a preocupação com sua aparência e com peso corporal por este motivo o adolescente pode ser afetado com facilidade e desenvolver distúrbios de ordem alimentar, autoimagem e dietas irregulares. Podem sofrer com ospadrões de beleza impostos pela mídia, conforme mencionado por Novaes (2006) apud Ribeiro (2016) a mesma circula crenças de fortes influências quanto a propagação de padrões de beleza a serem seguidos, endeusando corpos à prova de velhice e atendendo aos desejos sociais de perfeição.

Essa pesquisa tem como objetivo descrever e analisar as representações sociais dos estudantes do ensino médio, acerca das redes sociais, e as possíveis implicações na auto imagem desses jovens. Com vistas ao aprofundamento dos dados e o alcance da finalidade destacada, propõe como objetivos específicos:identificar as representações sociais dos estudantes do ensino médio acerca das redes sociais e as implicações na autoimagem; levantar referências bibliográficas sobre o assunto e analisar as respostas coletadas dos adolescentes.

\section{$2 \quad$ Métodos}

\subsection{Caracterização dos participantes}

Do grupo total, $56 \%(n=18)$ são meninas, $41 \%(n=13)$ são meninos e $3 \%(n=1)$ não quis se identificar. Ao que se refere às análises da renda familiar mensal dos grupos $60 \%$ dos adolescentes fazem parte da faixa de 1-3 salários mínimos $(n=19), 25 \%$ de 4-7 salários $(n=8)$, 6\% (n=2) menos de 1 salário mínimo e 9\% (n=3) acima de 10 salários mínimos. Na variável de idade, a idade mínima na participação do estudo era de 15 anos e máxima de 18 anos, na qual podemos observar a predominância de adolescentes com 17 anos, o que corresponde a 37,50\% da amostra.

$\mathrm{Na}$ distribuição dos participantes por estado civil, podemos observar que a maioria dos participantes moram com os pais ou parentes, 97\% $(n=31)$ e apenas $3 \%(n=1)$ mora com parceiro conjugal. Já conforme profissão ou ocupação $68,75 \%(n=22)$ dos jovens apenas 
estudam. Os demais exercem profissões que não necessitam obrigatoriamente da formação no ensino superior, como: jovem aprendiz 13\% ( $\mathrm{n}=4)$, operador de loja $3 \%(\mathrm{n}=1)$, auxiliar em floricultura 3\% ( $\mathrm{n}=1)$, auxiliar de programa social 3\% $(\mathrm{n}=1)$, autônomo $3 \%(\mathrm{n}=1)$, entregador $3 \%(\mathrm{n}=1)$ e vendedor $3 \%(\mathrm{n}=1)$.

Quanto à distribuição por ano de estudo houve predominância dos alunos do $3^{\circ}$ ano, com 53\% ( $n=17)$ de participação. Seguido por participantes do $2^{\circ}$ ano com $31 \%(n=10)$ e por último o $1^{\circ}$ ano com $16 \%(\mathrm{n}=5)$. Em relação ao estado civil, 65\% (n=20) não estavam namorando e $37 \%(\mathrm{n}=12)$ namoravam.

\subsection{Procedimento de coleta de dados}

Pesquisa de abordagem quantitativa, de natureza descritiva e do tipo transversal, pensada de acordo com o objeto proposto e sua especificidade. A estratégia multimetodológica de coletas de dados adotada combina quatro técnicas para a identificação dos diferentes planos das representações (conteúdo, estrutura, objetivação e práticas sociais). Desse modo, serão utilizadas para o alcance dos objetivos as seguintes técnicas: questionário para o levantamento do perfil socioeconômico, com questões fechadas concernentes à temática do estudo e para identificação do perfil sociodemográfico.

O instrumento foi aplicado online, logo após a explanação da pesquisa e da assinatura dos responsáveis ao Termo de Consentimento Livre e Esclarecido (TCLE), com um prazo de envio estipulado de trinta dias. Os dados quantitativos foram analisados pelas autoras de maneira informatizada, a partir da produção e análise de gráficos trabalhados no Sistema Microsoft Excel 2010, de acordo com os dados obtidos.

\section{$3 \quad$ Resultados}

Foi avaliado quantos participantes tinham Instagram ou Facebook e com unanimidade, todos tinham $(\mathrm{n}=32)$. Esse resultado é explicado pelo fácil acesso a essas ferramentas, principalmente na puberdade. As respostas dos participantes quando perguntados se teria alguém nessas redes sociais com quem o adolescente gostaria de se parecer fisicamente. 56\% $(n=18)$ dos participantes disseram que sim, o que nos faz refletir sobreos padrões de beleza que são difundidos, já que 55\% $(\mathrm{n}=10)$ das respostas positivas são do sexo feminino, que demonstram ser mais afetadas por essa dinâmica social.

Sobre se as publicações nas redes sociais, sejam por meio de fotos ou textos, podem influenciar negativamente na vida de alguém, $100 \%(n=32)$ dos participantes afirmaram que sim. O que nos leva a refletir a responsabilidade que as pessoas precisam ter em publicar qualquer conteúdo, sobretudo os que envolvem aspectos irreais do corpo. 
Quando perguntamos se achavam que as pessoas mentem ou fingem ser o que não são nas redes sociais, a resposta foi unânime que sim. Esse dado é relevante do ponto de vista mental e social, já que os resultados que veremos ao longo do artigo apontam uma influência negativa das redes na vida dos adolescentes, mesmo confirmando que todos os adolescentes participantes da pesquisa, afirmam que as pessoas que eles seguem nas redes sociais mentem. Esse dado indica que os mesmos sabem que alguns padrões de vida ou beleza aos que eles são expostos, podem ser irreais, mas parecem desconsiderar o fator de impacto causado pelo apelo das imagens, na vida de cada um.

Ao perguntar se alguém já fingiu ser o que não é em suas redes sociais, percebe-se que apenas 19\% $(\mathrm{n}=6)$ dos adolescentes entrevistados possuem contas falsas, mas quando pensamos nessa dinâmica dividida por gênero novamente as meninas são as mais afetadas, cerca de $17 \%$ $(n=3)$ das meninas entrevistadas e $15 \%(n=2)$ dos meninos, já haviam criado conta falsa.

Quando perguntado se já haviam se sentido triste por não parecer com alguém famoso nas redes sociais, pode-se perceber a predominância nas respostas positivas, este dado, mais uma vez, corrobora para o

entendimento de que as redes sociais influenciam negativamente a vida dos adolescentes, $75 \%(n=24)$ dos jovens que responderam ao questionário já se sentiram tristes na dinâmica citada. Outra inferência importante é que, cerca de $94 \%(n=17)$ das adolescentes do sexo feminino entrevistadas responderam esta pergunta de forma positiva, enquanto apenas $46 \%$ $(n=6)$ dos meninos afirmaram o mesmo. Novamente o destaque para predominância de resposta das meninas demonstra a problemática com a exposição exarcebada à padrões inalcançáveis.

Sobre os filtros usados nas fotos, $87 \%(n=28)$ dos participantes afirmam se sentirem mais bonitos (as) com algum filtro do Instagram. Apenas 13\% $(n=4)$ dos jovens responderam que nunca se sentiram mais bonitos (as) com algum filtro. A partir desse resultado, quando analisamos as respostas negativas, adolescentes que disseram que nunca se sentiram mais bonitos com algum filtro do Instagram, apenas 6\% $(n=1)$ de todas as meninas entrevistadas responderam o questionário dessa forma. Pode-se inferir uma baixa autoestima das meninas em relação à beleza, que pode ser potencializada pelos padrões de beleza continuamente difundidos.

Sobre possíveis mudanças na aparência física, $56 \%(\mathrm{n}=18)$ dos jovens responderam que gostariam de mudar alguma parte do corpo que não gostam ou para ficarem parecidos com alguém. Somente $44 \%(\mathrm{n}=14)$ estavam satisfeitos com suas aparências. Novamente as meninas são as mais afetadas por essa dinâmica,dentre as respostas positivas, cerca de $72 \%$ $(n=13)$ são do sexo feminino, acompanhados por $31 \%$ do sexo masculino $(n=4)$.

Por fim, 50\% dos participantes responderam que conhecem alguém que minta nas redes sociais e 50\% afirmam não conhecer. Pela análise do sexo, também não houve destaque em relação ao sexo feminino como nos gráficos anteriores. 
Tabela 1 - Distribuição das respostas por grupo

\begin{tabular}{|c|c|c|c|c|c|c|}
\hline \multirow{3}{*}{ Perguntas fechadas } & \multirow{3}{*}{ Grupo } & \multicolumn{4}{|c|}{ Respostas } & \multirow{3}{*}{ Total } \\
\hline & & \multicolumn{2}{|c|}{ Sim } & \multicolumn{2}{|c|}{ Não } & \\
\hline & & $f$ & $\%$ & $F$ & $\%$ & \\
\hline \multirow{3}{*}{ Você tem Instagram ou Facebook? } & Masculino & 13 & $100 \%$ & 0 & $0 \%$ & 13 \\
\hline & Feminino & 18 & $100 \%$ & 0 & $0 \%$ & 18 \\
\hline & $\mathrm{N} / \mathrm{I}$ & 1 & $100 \%$ & 0 & $0 \%$ & 1 \\
\hline \multirow{3}{*}{$\begin{array}{l}\text { Existe alguém nas redes sociais com quem você gostaria de } \\
\text { parecer fisicamente? }\end{array}$} & Masculino & 7 & $54 \%$ & 6 & $46 \%$ & 13 \\
\hline & Feminino & 10 & $56 \%$ & 8 & $44 \%$ & 18 \\
\hline & $\mathrm{N} / \mathrm{I}$ & 1 & $100 \%$ & 0 & $0 \%$ & 1 \\
\hline \multirow{3}{*}{$\begin{array}{l}\text { Acredita que publicações (sejam elas fotos ou textos) podem } \\
\text { interferir negativamente na vida de alguém? }\end{array}$} & Masculino & 13 & $100 \%$ & 0 & $0 \%$ & 13 \\
\hline & Feminino & 18 & $100 \%$ & 0 & $0 \%$ & 18 \\
\hline & $\mathrm{N} / \mathrm{I}$ & 1 & $100 \%$ & 0 & $0 \%$ & 1 \\
\hline \multirow{3}{*}{$\begin{array}{l}\text { Acha que as pessoas mentem ou fingem ser o que não são nas } \\
\text { redes sociais? }\end{array}$} & Masculino & 13 & $100 \%$ & 0 & $0 \%$ & 13 \\
\hline & Feminino & 18 & $100 \%$ & 0 & $0 \%$ & 18 \\
\hline & $\mathrm{N} / \mathrm{I}$ & 1 & $100 \%$ & 0 & $0 \%$ & 1 \\
\hline \multirow{3}{*}{$\begin{array}{l}\text { Você já fingiu ser alguém que não é nas suas redes sociais, } \\
\text { criando um perfil falso? }\end{array}$} & Masculino & 2 & $15 \%$ & 11 & $85 \%$ & 13 \\
\hline & Feminino & 3 & $17 \%$ & 15 & $83 \%$ & 18 \\
\hline & $\mathrm{N} / \mathrm{I}$ & 1 & $100 \%$ & 0 & $0 \%$ & 1 \\
\hline \multirow{3}{*}{$\begin{array}{l}\text { Já se sentiu triste por não ter um corpo ou um rosto parecido } \\
\text { com o de algum famoso(a) que você acompanha em alguma } \\
\text { rede social? }\end{array}$} & Masculino & 6 & $46 \%$ & 7 & $54 \%$ & 13 \\
\hline & Feminino & 17 & $94 \%$ & 1 & $6 \%$ & 18 \\
\hline & $\mathrm{N} / \mathrm{I}$ & 1 & $100 \%$ & 0 & $0 \%$ & 1 \\
\hline \multirow{3}{*}{$\begin{array}{l}\text { Você já se achou mais bonito (a) com o uso de algum filtro do } \\
\text { Instagram? }\end{array}$} & Masculino & 10 & $77 \%$ & 3 & $23 \%$ & 13 \\
\hline & Feminino & 17 & $94 \%$ & 1 & $6 \%$ & 18 \\
\hline & $\mathrm{N} / \mathrm{I}$ & 1 & $100 \%$ & 0 & $0 \%$ & 1 \\
\hline \multirow{3}{*}{$\begin{array}{l}\text { Já pensou em mudar algo no seu corpo ou rosto, para ficar } \\
\text { parecido com alguém das redes sociais? }\end{array}$} & Masculino & 4 & $31 \%$ & 9 & $69 \%$ & 13 \\
\hline & Feminino & 13 & $72 \%$ & 5 & $28 \%$ & 18 \\
\hline & $\mathrm{N} / \mathrm{I}$ & 1 & $100 \%$ & 0 & $0 \%$ & 1 \\
\hline \multirow{3}{*}{$\begin{array}{l}\text { Você conhece alguém que minta nas redes sociais, alterando } \\
\text { alguns de seus aspectos físicos ou pessoais ou criando um perfil } \\
\text { falso? }\end{array}$} & Masculino & 6 & $46 \%$ & 7 & $54 \%$ & 13 \\
\hline & Feminino & 9 & $50 \%$ & 9 & $50 \%$ & 18 \\
\hline & $\mathrm{N} / \mathrm{I}$ & 1 & $100 \%$ & 0 & $0 \%$ & 1 \\
\hline
\end{tabular}

Fonte: DUARTE, 2022

\section{Discussão}

Feita tais análises, alguns resultados chamam atenção, como por exemplo, a pergunta que avaliava se as redes sociais poderiam interferir negativamente na vida dos adolescentes, mais de $90 \%$ dos jovens afirmaram que sim. Esse aspecto, nos faz refletir a proporção das redes sociais na vida desses jovens e suas possíveis consequências, pois de acordo com Silva e Silva (2017) ao se desconectar, o se depara com um mundo totalmente diferente do que criou, 
consequência da falsa sensação de felicidade trazida pelas interações virtuais. Por isso é importante que os responsáveis verifiquem o conteúdo que esse adolescentes consomem afim de precaver problemas futuros, principalmente em relação a autoimagem.

Outras perguntas da pesquisa que obtiveram alta porcentagem de afirmação, como se gostariam de mudar alguma parte física do corpo ou se já se sentiram triste por não parecer com alguém que acompanhavam em suas redes sociais. Em ambos o caso, não podemos deixar de citar a alta porcentagem de resposta positiva, do sexo feminino. O mesmo ocorre na questão "Você já se achou mais bonito (a) com o uso de algum filtro do Instagram?". Esse dado pode ser explicado pela cobrança excessiva na inclusão das mulheres em padrões de beleza excludentes e inalcançáveis, padrões estes criados e incentivados pela sociedade machista e patriarcal onde só é belo e desejado aquilo que se encaixa nesses modelos irreais. Na pergunta "Já pensou em mudar algo no seu corpo ou rosto, para ficar parecido com alguém das redes sociais?" os resultados são preocupantes já que $72 \%$ das meninas e $31 \%$ dos meninos respondem que sim, de acordo com Vilas Bôas, Camargo e Rosa (2017) cirurgias estéticas tem crescido cada vez mais no mundo, isso aponta para a importância do assunto e compreensão do pensamento social dos indivíduos e seus grupos, como os jovens.

Segundo Silva (2017), como segmento social, os adolescentes são mais sensíveis às mudanças das tecnologias digitais. Por ser uma fase de muitas dúvidas e intensa mudança no que se refere o biológico, psicológico e social, eles adquirem mais fácil um vício. É nesta fase que eles buscam uma identidade e um lugar na sociedade.

A acrescentar, com tais resultados, é preciso atentar-se a um problema em potencial, pois os efeitos dessa influência pode piorar quando o jovem que consome mídias sociais tem uma autoimagem já distorcida, como nos casos de jovens com tendência a dismorfia corporal: de acordo com o Manual Diagnóstico e Estatístico de Transtornos Mentais (DSM-5), tais indivíduos se preocupam com um ou mais defeitos em sua aparência física e tal preocupação frequente gera uma ansiedade social com tendência esquiva (AMERICAN, 2014).

O resultado da pergunta "Acha que as pessoas mentem ou fingem ser o que não são nas redes sociais?" foi completamente inesperado. Os mesmos adolescentes que acham em unanimidade que as pessoas fingem ser o que não são nas redes sociais, são os mais influenciados. Esse dado indica que os mesmos sabem que alguns padrões de vida ou beleza aos que eles são expostos, podem ser irreais, mas parecem desconsiderar o fator de impacto causado pelo apelo das imagens, na vida de cada um. Este fator, sem dúvidas, merece maior atenção pois é extremamente curioso e de suma importância questionar a peculiaridade dessa relação estabelecida entre os adolescentes e as redes que usam, especialmente tentando entender mais a fundo essa passividade dos mesmos para com a internet. 


\section{Considerações Finais}

Durante a busca de referências bibliográficas e aplicação dos instrumentos de pesquisa na dinâmica cotidiana do fenômeno pesquisado, pode-se perceber um alinhamento de teoria e prática de forma que os resultados obtidos corroboram para o entendimento e visualização dos conhecimentos teóricos referenciados.

Ficou evidente que as redes sociais interferem na vida desses jovens, porém uma questão que merece maior atenção em estudos futuros é a de que os adolescentes do sexo feminino, como mostram a discussão e resultados da pesquisa, são constantemente mais afetados com questionamentos acerca da satisfação com sua autoimagem. Foram limitantes ao andamento deste trabalho: a escassez de artigos em português e publicados no Brasil referentes ao tema; o grupo escolhido para análise, por ser uma faixa etária ainda no limiar da menoridade a necessidade de autorização dos responsáveis por muitas vezes tornou-se um impeditivo ao uso dos dados obtidos (tanto por falta da documentação quanto por prostração por parte dos jovens).

Com isso, em um momento propício, por conta da baixa participação de adolescentes no estudo, será adicionado no material os dados qualitativos obtidos na pesquisa, afim que somar e aprofundar reflexões necessárias em relação ao tema. Almeja-se, também, que este trabalho contribua para o aprofundamento de estudos futuros sobre o tema, a fim de que propostas de intervenção e prevenção possam ser desenvolvidas e amplamente difundidas. Desta forma tornando esses jovens mais conscientes do seu consumo de conteúdo digital e possibilitando que desenvolvam uma análise mais crítica quanto a sua relação com a internet. 


\section{REFERÊNCIAS}

\section{AMERICAN PSYCHIATRIC ASSOCIATION. Manual diagnóstico e estatístico de} transtornos mentais. 5. ed. Porto Alegre: Artmed, 2014.

ARAUJO, Marivânia Conceição. As teorias das representações sociais e a pesquisa antropológica. Revista Hospitalodade. São Paulo, 2008.

BARDIN, Laurence. Análise de conteúdo. Lisboa: Edições 70, 1977.

COPETTI, Aline Vieira Sá; QUIROGA, Carolina Villanova. A influência da mídia nos transtornos alimentares e na autoimagem em adolescentes. Rev. Psicol. IMED, Passo Fundo , v. 10, n. 2, p. 161-177, dez. 2018 . Disponível em $<$ http://pepsic.bvsalud.org/scielo.php?script=sci_arttext\&pid=S2175-

50272018000200011\&lng=pt\&nrm=iso>. acessos em 06 set. 2020. http://dx.doi.org/10.18256/2175-5027.2018.v10i2.2664.

VILAS BÔAS, L. M.S.; CAMARGO, B. V. ; ROSA, A. S. . O pensamento social de universitários sobre beleza e cirurgia estética. Arquivos Brasileiros de Psicologia (Rio de Janeiro. 1979), v. 69, p. 187-206, 2017.

PASSOS, Michelle Delboni dos et al. Representações sociais do corpo: um estudo com adolescentes do Município do Rio de Janeiro, Brasil. Cadernos de Saúde Pública [online]. 2013, v. 29, n. 12 [Acessado 30 Julho 2021] , pp. 2383-2393. Disponível em: <https://doi.org/10.1590/0102-311X00027513>. Epub 29 Ago 2013. ISSN 16784464. https://doi.org/10.1590/0102-311X00027513.

RIBEIRO, V.M.M. (2016). A Psicologia Clínica e a Prevenção das Doenças da Beleza na Sociedade Brasileira Contemporânea (Monografia). Recuperado de: http://repositorio.uniceub.br/ bitstream/235/10354/1/21458612.pdf

SILVA, T. O.; SILVA, L. T. G. Os impactos sociais, cognitivos e afetivos sobre a geração de adolescentes conectados às tecnologias digitais. Psicopedagogia, São Paulo, v. 34, n. 103, pp. 87-97, 2017.

TEIS, Denize. TEIS, Mirtes. A abordagem qualitativa: a leitura no campo da pesquisa. UBI. Cleyton Lutz. 2006.

VERGÈS, P. SIMI - analyse de similitude de questionnaires et de donnees numeriques: manuel version 1.2. Aix-en-Provence, 1997. 